\title{
Reporting quotable yet untranslatable speech
}

\section{Observations of shifting practices by Japanese newspapers from Obama to Trump}

\author{
Kayo Matsushita \\ Rikkyo University
}

When a newsmaker (i.e., a newsworthy subject) is speaking or being spoken about in a foreign language, quoting requires translation. In such "translingual quoting" (Haapanen, 2017), it is not only the content of the speech but also its translatability that determines newsworthiness. While news media in some countries prefer indirect quotation, Japanese media favor direct quotes (Matsushita, 2019). This practice yields relatively clear source text (ST)-target text (TT) relationships in translingual quoting, especially when a political speech is directly quoted by newspapers, offering abundant data for news translation research (Matsushita, 2013, 2014, 2015, 2019). However, this research approach has been challenged by the rise of a public figure known for making headlines with his extemporaneous remarks: US President Donald J. Trump. Translingual quoting of Trump in the non-English media has proven at times a "nearly impossible quest" (Lichfield, 2016) because of the unique features of his utterances, such as unorthodox word choices, run-on sentences and disjointed syntax (Viennot, 2016). This difficulty is heightened for Japanese newspapers, which uphold a longstanding journalistic standard of reporting speech as faithfully as possible, even in the case of translingual quoting (Matsushita, 2019). Against this backdrop, this article examines the oftenconflicting relationship between "quotability" and "translatability" by analyzing how Japanese newspaper articles have quoted Donald Trump and his predecessor, Barack Obama, through comparison of original speeches and news texts produced by Japanese newspapers. The comparison shows that institutional conventions of Japanese newspaper companies regarding direct quotes are frequently neglected by the journalists trans-quoting Trump (e.g., changed to indirect quotes or reproduced less faithfully), leading to marked differences in the textual portrayals of the newsmakers in terms of eloquence and assertiveness.

Keywords: US President, political speeches, direct quotes, Japanese newspapers, news translation 


\section{Introduction}

According to journalist-turned-sociolinguist Allan Bell, "News is what people say more than what people do," and journalists essentially report on "talk not action" (Bell, 1991, p.53). This statement holds true in the case of Japanese newspapers, which are filled with direct quotes - ranging from public comments of political leaders to the words of angry protesters on the street.

Japanese newspaper reporters are responsible for translating quotes in languages other than Japanese. Van Doorslaer (2012) coined the term "journalator" to describe this unique role of "a newsroom worker who makes abundant use of translation" (van Doorslaer, 2012, p. 1049). This article uses the term in a narrower sense, referring to journalists who translate as needed, since professional news translators are largely non-existent in Japanese newsrooms (Matsushita, 2019). Journalators working for Japanese newspaper companies conduct "translingual quoting," the "process of news-writing in which the original discourse is translated during quoting" (Haapanen \& Perrin, 2019, p.16). Even in translingual quoting, Japanese journalators are expected to observe their professional norm (Chesterman, 1997) of reproducing utterances as faithfully as possible (Matsushita, 2019). This institutional convention of Japanese newspaper companies creates a relatively "stable" (Valdeón, 2015a) and traceable relationship between the ST (original utterance) and its TTs (direct quotes), which has enabled and stimulated detailed analyses of news texts involving translingual quoting (Matsushita, 2013, 2014, 2015, 2019).

This finding was an important breakthrough in news translation research because the unstable ST-TT relationship has been considered a major obstacle in the field. News translation is part of a collaborative and multifaceted news production process that defies "deconstruct[ion]... to determine which parts have been edited and which parts are the results of a translation act" (van Doorslaer, 2009, p. 85). This obstacle can be largely overcome by focusing on direct quotes in news articles. Direct quotes in print media are identifiable owing to visual cues such as quotation marks (Haapanen \& Perrin, 2017; Matsushita, 2019). Especially in newspaper reporting, the TTs (direct quotes in the news texts) and their corresponding STs (e.g., speeches and comments by politicians) are easily trackable due to their daily news cycle. Making use of this relationship, Matsushita (2019) observed unique findings in the coverage by Japanese newspapers, such as textual manipulations (e.g., omissions, additions, substitutions) at levels rarely seen in the case of monolingual quoting.

However, this approach, which seemed widely applicable in the Japanese context, has been challenged by the appearance of US President Donald Trump. Japanese newspapers - like others around the world - often write stories about President Trump's off-the-cuff remarks and random tweets but nearly as often fail 
to achieve linguistic and cultural equivalence because his utterances are difficult if not impossible to translate into any other language (Lichfield, 2016), let alone one as linguistically distant as Japanese (Osaki, 2017).

Given such circumstances, this article examines how Japanese newspaper articles have quoted President Trump by comparing them with those quoting President Obama. The original speeches given orally in English and the direct quotes in the written news texts produced by Japanese newspapers are compared and analyzed, with special attention to the relationship between "quotability" and "translatability." Following Clayman (1995), quotability in this article refers to the likelihood of an utterance being quoted based on narrative relevance, conspicuousness, and extractability (see Section 2.2 for a detailed description). Translatability is narrowly defined as the ability to reproduce an utterance in another language and present them as direct quotes with sufficient fidelity to suggest to readers that the speaker essentially said "every word between quotation marks" (The New York Times, 2008, Quotations, para. 1).

By comparing President Trump's quotes and those of President Obama, this article aims to illustrate how the institutional conventions of Japanese newspaper companies regarding direct quotes (e.g., frequent use of direct quotation, preference of direct over indirect quotation, and faithful reproduction of the original speech) have repeatedly been neglected in the coverage of President Trump. It also highlights the impact of such shifts and calls for further investigation of current translingual quoting practices in various mediascapes globally.

\section{Literature review}

\subsection{Overview of news translation research}

Until two decades ago, the crucial role of translation in international journalism which I refer to as news translation - had been largely ignored in research despite its visible and growing presence (Bielsa \& Bassnett, 2009; Holland, 2013). However, this situation has been changing recently as seen in the publication of two special issues on news translation: one titled "Culture and news translation" by the journal Perspectives published in 2015 (see Valdeón, 2015b, among others) and the second, an untitled special issue of Across Languages and Cultures in 2018 focusing on the methodology of news translation research (see Davier, Schäffner, \& van Doorslaer, 2018, for an overview). The increased attention on news translation as shown above and the inclusion of a related entry titled "Language, interpreting, and translation in the news media" in The Routledge Handbook of Translation Studies and Linguistics (Schäffner, 2018) are clear indications of the growing presence of news translation research within translation studies. 
The growing awareness of the uniqueness and importance of news translation, especially regarding translation practices of journalators, is seen among other disciplines such as applied linguistics as well as media and communication studies. It is not a coincidence that The Routledge Handbook of Language and Media, published just several months before the aforementioned volume on translation studies and linguistics, had a chapter titled "Multilingualism and media: Reconsidering practices and ideologies of media-linguistic research" (Ehrensberger-Dow, Perrin, \& Zampa, 2017), indicating interest across disciplines. Applying text progression analysis $^{1}$ to translation research, this body of work (Ehrensberger-Dow \& Perrin, 2009, 2015; Perrin, Ehrensberger-Dow, \& Zampa, 2017) succeeded in analyzing translation "processes" in the newsroom multidimensionally. The increased focus on research highlighting the translation process in news translation introduced above is highly relevant to this article. The most recent studies directly connected to this one are works by Haapanen and Perrin on quoting practices by the media (Haapanen \& Perrin, 2017) and on translingual quoting (Haapanen \& Perrin, 2019).

Following Haapanen and Perrin's (2019) assertion of the relevance of exploring the complex interconnectedness of translation and quoting, this article analyzes translingual quoting practices by Japanese newspapers. Before presenting the results of the analysis, however, key literature on global and Japanese quoting practices as well as the journalistic conventions on quoting will be presented to provide context for the research on translingual quoting.

\subsection{Global quoting practices}

Quoting practices have attracted researchers for decades because of their unique and irreplaceable role in news reporting. Clayman (1995) analyzed the US vicepresidential debate of 1988 and identified three basic elements that determine quotability: narrative relevance, conspicuousness, and extractability. According to Clayman, narrative relevance is "necessary but insufficient" (p.125) to fully explain why certain excerpts are quoted. There are other factors - conspicuousness and extractability - which, he notes, are more directly related to the "intrinsic properties of the source material" (p.126). According to Clayman (ibid., pp.126-127), conspicuous remarks are "intrinsically quotable, regardless of reporters' narrative preconceptions" and include "certain rhetorical formats, such as three-part lists and contrasts" as well as metaphorical formulations that are

1. A multimethod approach developed in the context of text production research, which combines methods such as ethnographic observation, interviews, computer logging, screen recordings, eye-tracking, and cue-based retrospective verbalizations (Ehrensberger-Dow \& Perrin, 2015). 
"unusual, colorful, or involve an analogic stretch." Poor extractability rules out speech requiring extensive contextualization (e.g., addition of background information). Since I am comparing the relative quotability of Trump and Obama, I focused mainly on these factors of conspicuousness and extractability that tend to reflect the nature and content of the particular remark regardless of its necessity in telling the intended story.

While the process for determining what to quote is fairly consistent globally, news cultures vary in their preferences for direct versus indirect quoting. In general, direct quotes are considered to be both impactful and useful for news reporting. According to Haapanen \& Perrin (2017), direct quotes mainly serve two functions: to attract audiences and to bolster credibility. Bell (1991) similarly describes the ability of direct quotes to add flavor and to present a "particularly incontrovertible fact," but additionally describes their ability to "distance and disown" and free the reporter from taking responsibility, especially in cases where politically or grammatically incorrect phrases were uttered (pp. 207-208).

Despite having such advantages, not all news cultures favor direct quotes (Bassnett, 2005). For example, Bassnett claims that the use of direct quotes in news writing would be perceived as "dumbing down" in some European countries, and thus articles are written using reported speech instead (ibid., p. 124). On the other hand, both tabloids and broadsheets prefer to use direct quotes in the UK, so that their articles "convey a greater sense of authenticity" which they believe is what the readers want (ibid.). The Japanese convention is similar to that of the UK in preferring direct over indirect quotes (Matsushita, 2019).

The practice of direct quotation also seems to vary, not only by country and institution but also by the social position of the newsmaker. Through analysis of news reports, Davis (1985) confirmed that "the higher the status of a speaker, the more direct the presentation" ( $\mathrm{p} .47$ ). This phenomenon is particularly relevant to this article given its focus on speeches by two US presidents. Leading the world's most powerful nation confers one of the highest statuses in the world. Consequently, it is expected that the media use direct quotes when writing about President Trump and President Obama, even if it involves translation.

Major news organizations have guidelines that instruct their reporters to pay special attention to direct quotes, stressing that they should be faithful reproductions of the original speech (Associated Press, 2019; Reuters, 2017; The New York Times, 2008). Haapanen \& Perrin (2017) summarize that journalistic guidelines define quoting as the "verbatim as possible rendering of an original utterance," specifying that "even if the linguistic form of the utterances needs slight modifications, its meaning must remain the same" (p.425). Although translated quotes can never be truly verbatim and the level of fidelity to the original tends to differ quite significantly (Haapanen, 2017; Haapanen \& Perrin, 2019), they are expected 
to represent the most accurate and complete translation a journalator can produce, at least in the case of Japanese newspapers (Matsushita, 2019).

\subsection{Japanese quoting practices}

In Japan, "direct speech" has been an enduring focal point of research on speech presentation among literary scholars. However, findings from this research often do not apply to direct speech in the context of journalism. Although a form of direct speech, direct quotes in Japanese can appear differently in a newspaper than in a novel. For example, while literary direct speech is typically indicated by reporting verbs and other grammatical markers in addition to quotation marks, this is not always the case with direct quotes in Japanese newspapers.

Satoh (2001), who analyzed how Japanese newspapers quote the Japanese Imperial Family, explains that in Japanese newspapers, direct speech is signaled by the presence of quotation marks for the entire quote while a mixture of direct and indirect speech is signaled by the presence of quotation marks for part of the quote (p.173). Satoh also explains that, "due to the lack of any markers to differentiate them, some instances of direct speech look identical to the possible indirect versions, except for the presence of quotation marks" and that in these cases "the presence of quotation marks is the only clue to distinguish direct speech from indirect speech" (Satoh, 2001, pp.173-174). Based on Satoh's finding and journalistic convention in Japan (Matsushita, 2019), "direct quotes" in this article are operationally defined as utterances enclosed in quotation marks. Some additional conditions are explained in the following section on methodology.

Another practice to keep in mind is that editors and other intermediaries working for Japanese newspapers are unlikely to edit content within quotation marks to improve the article (Matsushita, 2019). ${ }^{2}$ Even if other collaborators deem a change absolutely necessary, it will be communicated to the journalist who wrote the article before any edits are made, and the decision to change the quote ultimately belongs to the journalist. This practice has been confirmed through interviews with journalists who have translated US presidents' speeches for their articles (i.e., journalators) and backed by this author's personal newsroom work experience, as detailed in Matsushita (2019).

2. In other mediascapes, editors exercise more discretion over the content of the quotes (see Vandendaele, 2017, for a Belgian example). 


\section{Methodology}

The methodology of this study is mainly text analysis: a comparison of the original speech against direct quotes produced by the two largest Japanese newspapers. As Davier, Schäffner, and van Doorslaer (2018) point out, there is no established methodology unique to news translation research in translation studies. So far, it seems to be predominantly product-oriented (mainly text, discourse, or corpus analysis), although the trend of triangulation of textual and participant data is emerging (ibid., p.161). For example, Davier and Doorslaer (2018) suggest that the outcomes of textual analysis and the resulting hypotheses need to be triangulated with fieldwork, which includes observations and interviews with stakeholders. Process-oriented approaches developed at the intersection of text production analysis, media linguistics, and translation process research (see Section 2.1) are also examples of triangulation.

With the emergence of such multimethod approaches in mind, this article combines text analysis with findings from my prior work, which includes interviews with journalators from the two newspapers analyzed in this study (Matsushita, 2019). It also makes use of my 14 years of experience at one of the newspaper companies, the Asahi Shimbun, for insight into the inner workings of the newsroom as well as background knowledge regarding institutional conventions. The findings from the text analysis and the corresponding hypotheses are cross-examined with previously obtained information.

The specific research method is as follows. First, using online databases for the two largest daily newspapers in Japan, namely the Yomiuri Shimbun and the Asahi Shimbun, articles containing direct quotes of President Trump's and President Obama's spoken words (e.g., oral statements, speeches, comments) were collected (search terms and search periods will be explained in Section 4.2). Next, STs for each direct quote (video recordings or their full transcripts) were sought out using government websites and other sources. Articles with direct quotes for which the STs had been clearly identified were put to detailed analysis, mainly by comparing the ST with the TT as well as the TTs against each other.

Direct quotes with STs in written forms (e.g., written statements, executive orders, tweets) were excluded from the corpora for two main reasons: first, to focus on the more complex process of converting spoken words into written form while translating at the same time, and, second, to eliminate the impact of the technological changes that took place between 2009 and 2017 to allow for a direct comparison (for example, none of President Obama's direct quotes in 2009 were from his tweets). 


\section{Target of analysis}

\subsection{Japanese newspapers and journalators}

According to the Japan Newspaper Publishers \& Editors Association, ${ }^{3}$ there are more than a hundred newspapers in Japan. From national to regional to local, they enjoy a total circulation of approximately 40 million copies daily as of 2018, constituting one of the largest newspaper readerships in the world. For this study, I chose the two largest newspapers, Yomiuri Shimbun and the Asahi Shimbun (with circulations of approximately 8.34 million and 5.76 million respectively as of December $2018)^{4}$ to obtain a substantial number of articles from multiple sources for analysis.

Despite worldwide decline in newspaper readership, major Japanese newspaper companies maintain a network of correspondents stationed around the world, and the two newspapers have more than a dozen correspondents in the United States (The Japan Newspaper Publishers \& Editors Association, 2019). Roughly half are based in Washington, DC, with direct access to press conferences and other press opportunities provided by the US government. Not only are they responsible for covering daily news regarding the president and the White House, but they also have a deep understanding of the background of the president's remarks, which is needed when deciding what to quote (Matsushita, 2019). The quoting practices of the two papers analyzed are expected to be similar, even when conducting translingual quoting. Matsushita (ibid.) confirmed this by comparing how six major newspapers in Japan quoted President Obama's speeches: They exhibited no institutional differences in the proportion of quotes or in the ways in which they quoted. Therefore, this study does not focus on the difference between the TTs from the two newspapers but takes examples from both.

\subsection{Search criteria}

To find articles suitable for this study, the search terms 大統領 +トランプ [President + Trump] as well as 大統領 + オバマ [President + Obama] were used. The dates searched were January 21st to May 1st in 2017 for President Trump and the same range of dates in 2009 for President Obama. These cover the respective "honeymoon" periods (100 days of generally favorable press following inauguration),

3. https://www.pressnet.or.jp/english/data/circulation/circulationo1.php

4. According to the Japan Audit Bureau of Circulations (ABC). https://www.jabc.or.jp/abc 
during which similar, standardized coverage by the two newspapers would be expected for each president. ${ }^{5}$

The initial search returned 1703 Yomiuri articles and 1259 Asahi articles for President Trump and 745 Yomiuri articles and 767 Asahi articles for President Obama. ${ }^{6}$ To distill the corpora to only the articles containing substantial direct quotes translated by journalators, all cases meeting the following criteria were excluded manually:

1. Articles without the president's direct quotes

2. Articles written by external contributors

3. Articles based solely on expert interviews

4. Quotes in the reader's column

5. Articles only quoting wire reports and other print media that are not readily accessible

6. Articles only quoting radio and TV broadcast news that are not readily accessible

7. Articles only quoting unidentifiable media reports (e.g., "according to the local media")

8. Articles only containing quotes that are presented as hearsay

Criterion 1 was applied first to eliminate all articles lacking direct quotes from the presidents. As mentioned earlier, the direct quotes in this study were extracted using the presence of quotation marks as identifiers following Satoh (2001). Then, additional conditions were applied to exclude words within quotation marks that were not reproductions of specific identifiable utterances. For example, quotes in headlines, which Satoh calls "elliptical and ambiguous in terms of the voice" (ibid., p.172), were not counted. This left only the quotes embedded in the articles for analysis. In addition, scare quotes ${ }^{7}$ (Bell, 1991, p. 208) as well as other short phrases with quotation marks signifying "so-called" (ibid.) and campaign slogans such as "Yes We Can" and "Make America Great Again" were removed because these special usages of quotation marks generally do not indicate that the words were

5. U.S. presidents are inaugurated on January 20 th and the 10oth day is April 29th. However, due to the time difference, Japanese newspapers' coverage of the new administration starts on January 21st, and special coverage summarizing the first 100 days is typically published on May 1st.

6. The search criteria excluded the local news pages but included all regional editions (Osaka, Nagoya, etc.) of the two papers, resulting in multiple counts of the same direct quotes in some cases because the same article appeared in different editions. This could not be avoided since Yomiuri's database did not give the option of excluding regional editions, and the two newspapers needed to be compared using the same search criteria.

7. Scare quotes are quotation marks used to draw attention to a word or phrase, often to show doubt or disdain toward it. An example is provided in Bell (1991, p. 208). 
actually uttered by a specific speaker. Also excluded were cases in which the content enclosed in quotation marks were presented as a summary of the speaker's previously known stance or opinion rather than as what the speaker actually said.

Criteria 2 to 4 were needed to select direct quotes that were translated by the journalators of the two newspapers. ${ }^{8}$ Criteria 5 to 8 were added to factor out cases with inaccessible STs. The remaining articles were further scrutinized, and only those with STs identifiable by date and keywords/phrases and obtainable from credible sources (e.g., government websites, transcripts, and recordings made accessible by major media organizations) were put to comparative analysis to examine differences in translingual quoting practices. With these considerations, the target of analysis for this study was pared down to 243 Yomiuri articles and 209 Asahi articles for President Trump and 160 Yomiuri articles and 196 Asahi articles for President Obama (see Table 1).

\section{Key findings}

The comparative analysis explained in the previous section resulted in several interesting findings regarding the shift in translingual quoting practices by the two Japanese newspapers between their coverage of the first 100 days of President Obama's presidency and those of President Trump's presidency eight years later. The findings can be characterized as differences in (1) frequency (how often the articles contained direct quotes), (2) length (how long the quoted content was), and (3) dispersion (the distribution of articles with direct quotes over the 100-day period). Frequency can be a measure of the relative quotability of each president's utterances, based mostly on conspicuousness and extractability given the aforementioned standardization of coverage in the first 100 days of a US presidency. The length of the quote represents the proportion of the utterance deemed quotable by the journalators. Dispersion of the quotes reflect how the journalators' decisions regarding quotability changed over time. Representative examples are provided for each of the three findings to corroborate my analysis.

8. If there are direct quotes of the presidents' utterances in these three cases, it is likely that the utterances were translated into Japanese by the expert, interviewee or the reader. Even if the contribution was made or the interview was conducted in English, it remains unclear who did the translation. Therefore, these cases were excluded. 


\subsection{Frequency of quotes}

The inauguration of President Obama, who was the first African-American to assume the position, was undoubtedly a newsworthy topic for the Japanese media, and his first 100 days in office generated an unprecedented number of news articles. However, this record was soon exceeded by his successor who was even more newsworthy in several respects: Trump, a businessman known for his scandalous comments and behavior both before and during the presidential campaign, promoted himself as a Washington outsider and became the first president without prior political or military experience.

A comparison of the total number of articles that the two largest newspapers published in the targeted period of analysis shows the increased attention clearly: close to 3,000 articles in the case of President Trump, almost doubling President Obama's count of slightly more than 1,500. By these numbers, President Trump was a more newsworthy subject for the two Japanese newspapers than President Obama. However, by focusing on the number of articles with direct quotes, a different phenomenon surfaces. Between the two newspapers, $23.5 \%$ of the articles mentioning President Obama included direct quotes from his oral statements, speeches, or remarks made during various press encounters and interviews, while only $15.3 \%$ of the articles mentioning President Trump featured direct quotes from him (see Table 1).

Table 1. Number of articles and proportion with direct quotes (DQs)

\begin{tabular}{lccccccc}
\hline & \multicolumn{3}{c}{ Trump } & & \multicolumn{3}{c}{ Obama } \\
\cline { 2 - 3 } \cline { 7 - 8 } & Total & w/DQs & \% & & Total & w/DQs & \% \\
\hline Asahi & 1259 & 209 & 16.6 & & 767 & 196 & 25.6 \\
Yomiuri & 1703 & 243 & 14.2 & & 745 & 160 & 21.5 \\
Total & $\mathbf{2 9 6 2}$ & $\mathbf{4 5 2}$ & $\mathbf{1 5 . 3}$ & & $\mathbf{1 5 1 2}$ & 356 & $\mathbf{2 3 . 5}$ \\
\hline
\end{tabular}

It is hard to give definite reasons as to why this pattern emerges, but both newspapers did quote President Obama more frequently in writing news articles about him than in the case of President Trump. The fact that articles about President Trump were twice as numerous as those about his predecessor during the targeted period combined with Japanese newspapers' tendency to favor direct quotes, as discussed earlier, leads one to expect more articles to contain direct quotes from his utterances, but that was not the case. In other words, President Trump's quotability was lower than that of his predecessor, although his newsworthiness was higher. This phenomenon can be explained in part by the untranslatability of President Trump's words, as seen in the example below. 
In an article published on February 21, 2017, about remarks made by thenSecretary of Defense James Mattis during his visit to Iraq, the Asahi Shimbun (Minemura, 2017) partially quoted an article by Reuters (Stewart, 2017). ${ }^{9}$ After the words "According to Reuters," it quoted two remarks by Secretary Mattis with quotation marks but quoted President Trump's comment indirectly without quotation marks despite the fact that all three quotes appeared in the same paragraph.

The original Reuters article quoted President Trump telling Central Intelligence Agency (CIA) staff in January, "We should have kept the oil. But okay. Maybe you'll have another chance," implying that the CIA should have seized Iraq's oil after overturning Saddam Hussein in 2003. The Asahi article simply said トランプ 氏は米中央情報局（CＩＡ）で1月、イラクの石油を確保すべきだった と発言 [Mr. Trump had said at the CIA in January that Iraq's oil should have been secured] without putting the original comment in quotation marks. ${ }^{10}$ Since one of Secretary Mattis' remarks ("We're not in Iraq to seize anybody's oil") was considered to be in response to the previous comment in January by President Trump and, therefore, placed right after the indirect quote in the same sentence, it would have made more sense to quote both of them directly had no translation been needed. Moreover, President Trump's comment ("We should have kept the oil") was directly quoted in the English language media, including major newspapers in the US, the UK, and Australia, indicating that the quotability of the comment both in terms of conspicuousness and extractability was high. This example shows how untranslatability (i.e., the inability to reproduce an utterance as an acceptable quote in a different language as explained in Section 1) can overrule the Japanese newspapers' institutional convention regarding direct quotes.

Another interesting example was found in a Yomiuri article dated April 27, 2017 (Oki, 2017), regarding a joint statement made by core members of the Trump Administration (Secretary of State Rex Tillerson, Secretary of Defense James Mattis, and Director of National Intelligence Dan Coats). The statement itself was directly quoted four times in the article while President Trump, who was also present at the briefing, was introduced only as トランプ大統領は冒頭の約 5 分間、あい さつした [President Trump gave a remark for the initial five minutes] with no direct quotes of his own. This was not the only case in which the spokesperson or other relevant cabinet members were quoted instead, even when President Trump had given his own remarks on the same topic that day. These articles were excluded from the corpora during the initial screening process because they contained no

9. This article was included in the analysis because the quoted comments in the Reuters article were made in public, and, in each case, either the official transcript or a video recording was available for verification.

10. All the back translations are mine. 
direct quotes from President Trump. Such examples suggest that Japanese newspapers apply different practices when quoting individuals whose speech is difficult to translate, resulting in a lower percentage of articles containing their direct quotes.

\subsection{Length of quotes}

There was a noticeable difference in the length of quotes as well. President Obama's direct quotes were found to be longer, often including multiple sentences in one quote, compared with shorter quotes (including one-word or single-phrase quotes) typical in the case of President Trump. However, because there are no spaces between words in Japanese, and, therefore, an accurate word count comparable to that of English is not possible, it was difficult to measure and present the difference numerically. To compensate for the lack of quantitative data, some noteworthy examples from the 808 articles analyzed ( 452 for Trump and 356 for Obama) are presented below.

In the case of President Obama, one of his longest direct quotes was found in an article about his televised interview with the Saudi-owned pan-Arab broadcaster Al Arabiya. ${ }^{11}$ In this mid-length article of 801 Japanese characters written by one of the Washington correspondents of the Asahi Shimbun, President Obama's utterances were quoted directly seven times (totaling 420 characters), two of which had three and four sentences apiece enclosed in quotation marks (Umehara, 2009). Although the number of Japanese characters used does not automatically represent the length of a quote, ${ }^{12}$ the fact that more than half of the article was filled with direct quotes clearly indicates the Japanese journalator's intention to quote President Obama at length. On the contrary, in a Yomiuri article about then-Attorney General Jeff Sessions' allegations of perjury, President Trump was quoted three times, but only in short segments such as 完全に [total] and 恐らくしたと思う [probably did] (Kuromi, 2017).

In one of the articles, however, President Trump was quoted at length, though with significant TT manipulations by the journalators. This was a case in which he was asked about a shooting incident in Paris at a press conference after his meeting with Italian prime minister Paolo Gentiloni on April 2oth. An official transcript shows that he answered in the following manner:

11. http://www.nbcnews.com/id/28870724/ns/politics-white_house/t/full-transcript-obamasal-arabiya-interview/\#.XOaVk1P7QWo

12. The number of Japanese characters used in a word can vary significantly. Therefore, the word count can be low even if many characters are used. 
ST: Well, first of all, our condolences from our country to the people of France. Again, it's happening, it seems. I just saw it as I was walking in, so that's a terrible thing and it's a very, very terrible thing that's going on in the world today. But it looks like another terrorist attack. And what can you say - it just never ends. We have to be strong and we have to be vigilant. And I've been saying it for a long time.

(US Embassy \& Consulates in Italy, 2017)

The Asahi Shimbun quoted this comment by compressing seven sentences to just three (Aota \& Kida, 2017):

TT: フランス国民に哀悼の意を表明する。またテロリストによる攻撃の ようだ。我々は強くなければならず、警戒を欱らないようにしなければ ならない

[I express (our) condolences to the people of France. It seems to be another terrorist attack. We have to be strong and vigilant.]

(Asahi Shimbun, April 21, 2017, evening edition, p.1)

By comparing the ST with the TT, it is evident that the journalator intentionally omitted many words so that the quote would be less repetitive, more straightforward and, above all, easier to translate. However, it cannot be denied that this process has also stripped away the emotional impact of President Trump's informal rhetorical style in expressing his condolences and rallying against terrorism.

While President Obama was regularly praised for "his regular flow, his impeccable diction, his eloquence, his constructed and logical speeches, his self-deprecation, his fine humor, often blended with irony calculated to the millimeter," President Trump has been criticized for "breaking the codes of discourse, using a limited vocabulary and a chopped and disjointed syntax" (Viennot, 2016, my translation). This difference in speech style might explain in part why journalators preferred to use President Obama's quotes at length - to make the article itself more appealing - when compared to those of President Trump. However, it can also be argued that the journalators portrayed President Trump as being less articulate and assertive than he really is because of how they simplified his speech to make it more translatable, increasing extractability but losing conspicuousness in the process.

\subsection{Dispersion}

Another tendency observed in the comparative analysis concerned the distribution of the articles with direct quotes over time. Apart from obvious spikes during special events such as the inauguration ceremony as well as his first summit meeting with the Japanese prime minister, President Obama was quoted at a fairly constant rate throughout his first 100 days. In the case of President Trump, however, more than half of the articles analyzed were concentrated in his first 30 days 
(233 articles out of the total 452), and the number dwindled toward the end of the honeymoon period (only 25 in the last 10 days).

A detailed analysis yielded one possible reason for this phenomenon related to the trend of fact-checking President Trump's comments that emerged during the presidential campaign. Since President Trump tended to frequently make factual errors in his remarks and tweets, media around the world, including Japanese newspapers, published articles that aimed to verify his assertions, especially in the beginning of his presidency. ${ }^{13}$ This movement resulted in a number of mistakes being uncovered in his remarks before and after his inauguration and may have led the media to take caution when quoting him directly because one of the key functions of direct quotation is to add credibility (Haapanen \& Perrin, 2017). Although Japanese newspapers, in general, prefer to use direct quotes as previously mentioned, it would be high risk to quote statements by someone established as having propagated factual errors, even more so when translation is involved since the readers might assume that the journalator - not the newsmaker - was the one who made the error. I consider this "unreliability" to be an additional determinant of quotability and worthy of further research.

\section{Conclusion}

Previous sections have illustrated a clear shift in the way translingual quoting is practiced by two major newspapers in Japan. Noticeable differences emerged when articles quoting President Obama's utterances and those of President Trump were compared. President Obama's statements and remarks were quoted more often and in longer segments, sometimes taking up more than half of the space given to the article. In contrast, direct quotes from President Trump's comments were less frequent and shorter. Although the number of articles written was more than twice as many as those of President Obama, President Trump's oral remarks seemed to be unpopular (i.e., less quotable) among the journalators of the two newspapers analyzed. Since this was not a trend observed in the English language media as seen in the case of "We should have kept the oil" (Section 5.1), it can be argued that these differences are related to the difference in the translatability of the two presidents' utterances when quoting into Japanese.

13. See for example the results of the Washington Post's Fact Checker team's findings which counted 492 false or misleading claims made by President Trump in the first 100 days of his presidency: https://www.washingtonpost.com/graphics/politics/trump-claims/?noredirect $=$ on\&utm_term $=.77$ ce $_{3}$ d2boed 7 
The examples presented in the preceding sections provided support for this argument. Journalators seemed more willing to translate President Obama's words even when it meant translating several sentences for a single quote. In contrast, journalators tended not to use direct quotes in the case of President Trump even when it seemed to make more sense to do so. While these observations and analyses would be strengthened by further investigation, especially through interviews with the journalators who wrote the articles analyzed, I believe that the findings highlighted in this article can contribute to deepening our understanding of the contexts that influence translingual quoting practices.

\section{Future implications}

Although my analysis yielded meaningful findings, there are several avenues of investigation I did not pursue that would contribute to a richer, more holistic interpretation of these findings. First, as mentioned above, interviews with journalators would be desirable in order to verify the findings of this study and to add more reasons as to why the shifts in translingual quoting practices were observed between the news coverages in 2009 and in 2017.

Second, the impact of the changes in quoting practices on the readers also deserves to be explored. The shift seemed justifiable from the perspective of the news production process, but this does not necessarily mean that the readers are satisfied with the new style. Japanese readers are already familiar with how President Trump looks and acts through TV and various online sources, and it is highly likely that they are interested in the content of his speech as well. One way to meet their expectations would be to use direct quotes because doing so puts the readers "directly in touch" with the subject (Haapanen \& Perrin, 2017, p. 438). Conducting a survey to find out the needs of different types of media consumers (e.g., readers, viewers, and listeners) might be an approach worth exploring.

Last, it would be interesting to investigate how President Trump's utterances are being quoted by newspapers in other Asian countries, especially China and South Korea. Journalators working for Chinese and Korean newspapers are likely facing similar difficulties with translingual quoting of President Trump. Since journalism practice elsewhere in the world tends to differ when compared to that of Japanese newspapers, analyzing the translations of the same STs might result in different findings. With the next US presidential election approaching in November 2020, now may be an opportune time for multilingual collaborators among scholars of journalism and of translation studies to connect. I hope that this article will serve as a starting point for such future collaborations. 


\section{References}

Aota, H., \& Kida, T. (2017, April 21). Pari Shanzerize-dōri, keikan ni jūgeki san nin shishō: ISkei, hankō seimei, daitōryō-sen no tōhyō chokuzen [Paris Champs-Elysées, gun fires at policemen, three injured or killed: IS-related group claims responsibility, just before the presidential election]. Asahi Shimbun, evening edition, p. 1.

Associated Press. (2019). The Associated Press stylebook 2019. Retrieved from <https://www .apstylebook.com/>

Bassnett, S. (2005). Bringing the news back home: Strategies of acculturation and foreignisation. Language and Intercultural Communication, 5(2), 120-130. https://doi.org/10.1080/14708470508668888

Bell, A. (1991). The language of news media. Oxford: Blackwell.

Bielsa, E., \& Bassnett, S. (2009). Translation in global news. Abingdon: Routledge.

Chesterman, A. (1997). Memes of translation: The spread of ideas in translation theory. Amsterdam: John Benjamins. https://doi.org/10.1075/btl.22

Clayman, S.E. (1995). Defining moments, presidential debates, and the dynamics of quotability. Journal of Communication, 45(3), 118-146. https://doi.org/10.1111/j.1460-2466.1995.tboo746.x

Davier, L., \& van Doorslaer, L. (2018). Translation without a source text: Methodological issues in news translation. Across Languages and Cultures, 19(2), 241-257. https://doi.org/10.1556/084.2018.19.2.6

Davier, L., Schäffner, C., \& van Doorslaer, L. (2018). The methodological remainder in news translation research: Outlining the background. Across Languages and Cultures, 19(2), 155-164. https://doi.org/10.1556/084.2018.19.2.1

Davis, H.H. (1985). Discourse and media influence. In T.A. van Dijk (Ed.), Discourse and communication: New approaches to the analysis of mass media discourse and communication (pp. 44-59). Berlin: De Gruyter. https://doi.org/10.1515/9783110852141.44

Ehrensberger-Dow, M., \& Perrin, D. (2009). Capturing translation processes to access metalinguistic awareness. Across Languages and Cultures, 10(2), 275-288. https://doi.org/10.1556/Acr.10.2009.2.6

Ehrensberger-Dow, M., \& Perrin, D. (2015). Applying a newswriting research approach to translation. In M. Ehrensberger-Dow, S. Göpferich, \& S. O’Brien (Eds.), Interdisciplinarity in translation and interpreting process research (pp. 79-94). Amsterdam: John Benjamins. https://doi.org/10.1075/bct.72.07ehr

Ehrensberger-Dow, M., Perrin, D., \& Zampa, M. (2017). Multilingualism and media: Reconsidering practices and ideologies of media-linguistic research. In C. Cotter, \& D. Perrin (Eds.), The Routledge handbook of language and media (pp. 373-387). Abingdon: Routledge. https://doi.org/10.4324/9781315673134-28

Haapanen, L. (2017). Quoting practices in written journalism. Article-based doctoral dissertation, University of Helsinki. https://helda.helsinki.fi/handle/10138/174618

Haapanen, L., \& Perrin, D. (2017). Media and quoting. In C. Cotter, \& D. Perrin (Eds.), The Routledge handbook of language and media (pp. 424-441). Abingdon: Routledge. https://doi.org/10.4324/9781315673134-31 
Haapanen, L., \& Perrin, D. (2019). Translingual quoting in journalism: Behind the scenes of Swiss television newsrooms. In L. Davier, \& K. Conway (Eds.), Journalism and translation in the era of convergence (pp. 15-42). Amsterdam: John Benjamins. https://doi.org/10.1075/btl.146.01haa

Holland, R. (2013). News translation. In C. Millán, \& F. Bartrina (Eds.), The Routledge handbook of Translation Studies (pp. 332-346). Abingdon: Routledge.

Kuromi, S. (2017, March 3). "Beidaitōryōsen no kyōgi sezu": Gishō giwaku no shihō chōkan, Rotono sesshoku shakumei ["No consultations on US presidential election": Attorney General suspected of perjury explains his connection with the Russians]. Yomiuri Shimbun, evening edition, p. 3.

Lichfield, G. (2016, November 26). Inside the nearly impossible quest to translate "Make America Great Again" into Spanish. QUARTZ. Retrieved from <https://qz.com/845744 /inside-the-nearly-impossible-quest-to-translate-make-america-great-again-intospanish/>

Matsushita, K. (2013). Obama daitōryō no enzetsu o Nihon no shinbun wa ikani hōjitaka: Chokusetsu inyō to shōryaku o meguru kōsatsu [How President Obama's speeches were translated by the Japanese newspapers: A discussion on direct quotation and omission]. Media, English and Communication, 3, 31-46.

Matsushita, K. (2014). Risk management as a theoretical framework for analyzing news translation strategies. Invitation to Translation Studies, 12, 83-96. Retrieved from <http:// honyakukenkyu.sakura.ne.jp/shotai_vol12/05_vol-12_Matsushita.pdf>

Matsushita, K. (2015). Omission as a key strategy in Japanese news translation: A case study of President Obama's speeches. In A. Fuertes, \& E. Torres-Simón (Eds.), And translation changed the world (and the world changed translation) (pp. 75-88). Newcastle upon Tyne: Cambridge Scholars.

Matsushita, K. (2019). When news travels east: Translation practices by Japanese newspapers. Leuven: Leuven University Press.

Minemura, K. (2017, February 21). Beikokubōchōkan, Iraku hōmon: Abadi shushō to kaidan, kankei shūfuku hakaru [US Secretary of Defense visits Iraq: Meets with Prime Minister Abadi, tries to restore relationship]. Asahi Shimbun, evening edition, p. 2.

Oki, S. (2017, April 27). Taikita atsuryoku "seisai, gaikō de": Bei san chōkan kyōdō seimei, jōkazengiin ni setsumeikai [Pressure against North Korea "through sanctions and diplomacy": Joint statement by the three heads, briefing to all upper and lower house members]. Yomiuri Shimbun, evening edition, p. 1.

Osaki, T. (2017, February 17). Japan's interpreters struggle to make sense of 'Trumpese.' The Japan Times. Retrieved from <https://www.japantimes.co.jp/news/2017/02/17/national /japans-interpreters-struggle-to-make-sense-of-trump-speeches/\#.Wzd9-af7Rdg>

Perrin, D., Ehrensberger-Dow, M., \& Zampa, M. (2017). Translation in the newsroom: Losing voices in multilingual newsflows. Journal of Applied Journalism \& Media Studies 6(3), 463-483. https://doi.org/10.1386/ajms.6.3.463_1

Reuters. (2017). Handbook of journalism. Retrieved from <http://handbook.reuters.com/index .php?title $=\mathrm{Q} \&$ direction $=$ next\&oldid $=7517>$

Satoh, A. (2001). Constructing imperial identity: How to quote the Imperial Family and those who address them in the Japanese press. Discourse \& Society, 12(2), 169-194. https://doi.org/10.1177/0957926501012002003 
Schäffner, C. (2018). Language, interpreting, and translation in the news media. In K. Malmkjaer (Ed.), The Routledge handbook of Translation Studies and Linguistics (pp. 327-341). Abingdon: Routledge.

Stewart, P. (2017, February 20). Trump's defense chief: "We're not in Iraq to seize anybody's oil." Reuters. Retrieved from < https://www.reuters.com/article/us-mideast-crisis-iraqmattis-idUSKBN15ZoKo>

The Japan Newspaper Publishers \& Editors Association. (2019). Nihon Shimbun Nenkan [Japan Newspaper Annual].

The New York Times. (2008). Guidelines on integrity. Retrieved from <https://www.nytimes .com/editorial-standards/guidelines-on-integrity.html>

Umehara, T. (2009, January 28). Obama daitōryō Isuramu to no taiwa kyōchō: Hatsu no tandoku kaiken wa Chūtō TV [President Obama emphasizes dialogue with Islam: First exclusive interview with a Middle Eastern broadcaster]. Asahi Shimbun, evening edition, p. 2.

US Embassy \& Consulates in Italy. (2017). Remarks by President Trump and Prime Minister Gentiloni of Italy in joint press conference. Retrieved from $<$ https://it.usembassy.gov /remarks-president-trump-prime-minister-gentiloni-italy-joint-press-conference/>

Valdeón, R.A. (2015a). (Un)stable sources, translation and news production. Target 27(3), 440-453. https://doi.org/10.1075/target.27.3.07val

Valdeón, R.A. (2015b). Fifteen years of journalistic translation research and more. Perspectives, 23(4), 634-662. https://doi.org/10.1080/0907676X.2015.1057187

Vandendaele, A. (2017). The newsroom's last line of defence: A linguistic ethnographic investigation into newspaper sub-editing (Unpublished doctoral dissertation). Ghent University, Belgium.

van Doorslaer, L. (2009). How language and (non-) translation impact on media newsrooms: The case of newspapers in Belgium. Perspectives, 17(2), 83-92. https://doi.org/10.1080/09076760903125051

van Doorslaer, L. (2012). Translating, narrating and constructing images in journalism with a test case on representation in Flemish TV news. Meta, 57(4), 1046-1059. https://doi.org/10.7202/1021232ar

Viennot, B. (2016). Pour les traducteurs, Trump est un casse-tête inédit et désolant [For translators, Trump is an unprecedented and disheartening puzzle]. Slate FR. Retrieved from <http://www.slate.fr/story/131087/traduire-trump-mourir-un-peu>

\title{
Address for correspondence
}

\author{
Kayo Matsushita \\ Rikkyo University \\ 3-34-1, Nishi-Ikebukuro \\ Toshima-ku, Tokyo 171-8501 \\ Japan \\ kayo.matsushita@rikkyo.ac.jp
}

